\section{CONIUM IN THE TREATMENT OF ACUTE MANIA.}

BY J. CRICHTON BROWNE, M.D., F.R.S.E.,

TEDICAL diRECTOR, WEST RIDING ASTLUM.

(Conclided from page 183.)

WITH the view of determining the relative duration of cases of acute mania treated with conium and with other remedies, I have contrasted twelve cases from each category. As the result of that contrast, I find that twelve consecutive cases treated from the first with conium, admitted subsequent to Feb. 25th, 1871, and since discharged recovered, had an average duration, as measured by residence in the asylum, of 102 days; whereas twelve consecutive cases treated with other remedies, such as bromide of potassium, canabis indica, chloral, and digitalis, admitted subsequent to October 1st, 1870, and since discharged recovered, had an average duration, as measured by residence in the asy$l_{\mathrm{um}}$, of 150 days. This shows a balance of 48 days in favour of conium. It will be seen, from the cases reported below, that when conium was used, that period of convalescence which it is thought prudent to interpose betwaen the date when recovery might be called complete and the date of discharge from the asylum was in no instance unusually shortened. In some cases it might be thought that it was unnecessarily prolonged. So rapid and decisive were the beneficial effects of the remedy that it was feared at first they might prove transitory, and that, as is not seldom the case when recovery is sudden, a relapse might be looked for. Experience having now taught that this fear is groundless, a considerable curtailment of the term of medical super. vision may be henceforth safely conceded. Indeed, so prompt is recovery, as a rule, under the conium treatment, that it appears that the necessity of removal to an asylum may be obviated in some cases of acute mania if it is had recourse to, and judiciously conducted, in their initial stage.

The curative effects of conium in acute mania are not limited to those cases in which that remedy is used from the outset of the disorder. Eight patients in this asylum in whom other methods of treatment had been first employed have derived marked advantage from the substitution of conium for other drugs.

To indicate the value of conium in acute mania more conclusively than can be done by general statements or numerical results, I have drawn up epitomes of some of the cases in which its therapeutical worth has been clearly exemplified in this asylum. Before adding these epitomes, I bave only to express my conviction that the conium treatment of acute mania will speedily recommend itself, to those who use it rightly, as the most efficacious mode of dealing with that form of mental disease. In order, however, to secure its benefits, two conditions must be observed: firstly, the preparation used must be good and active; secondly, the doses administered must be adequate in amount. The succus conii is certainly the most trustworthy preparation of the drug, and is that which has of late been used exclusively here. Even the succus, however, varies in activity in an extraordinary degree. Some of it is absolutely inert. That which has been found most reliable by me has been obtained from two of the London houses named by Dr. Harley, from an Edinburgh and from a German firm. As to the doses required, I can strongly corroborate Dr. Harley's assertion, that they must be sufficient to produce the physiological action of the drug in order to prove beneficial in disease. I can also support his conclusion, that the effect of conium is inversely as the motor activity of the individual to whom it is given. This being so, it must be evident that in acute mania, in which motor activity is at a maximum, very large doses will be essential. I have given a woman labouring under acute mania as much as two ounces of succus conii at one dose, and have repeated this every four hours for two days. This was, however, an extreme case, and the patient had been gradually habituated to the use of the drug. As a rule, I have commenced with two drachms of the succus for a woman, and three drachms for a man ; and have rapidly increased the dose until I have noticed some cessation of restlessness, or signs of lassitude or weakness of the limbs.
It is rarely that a dose of one ounce or ten drachms requires to be exceeded; and sometimes improvement begins with the very first administration, in which case no increase of quantity is necessary.

Case 1.-Lydia F-_, aged thirty-five, housewife, from Barnsley, admitted March 31st, 1871, having been insane for one month. Is a member of a family of drunkards; her sister hanged herself. When adnitted she was in a state of violent maniacal excitement and great exhaustion, groaning, shouting, and struggling; pupils dilated and unequal; face flushed; refuses food, and is sleepless. Ordered succus conii, two drachms three times a day.-A pril 2nd: Much quieter; takes ber food and sleeps well.-4th: Perfectly calm, and employs herself in sewing; pupils contracted and sensitive. - May 16th: Discontinue medicine.-Jane 20th : Is passing through a protracted stage of slight dementia characterised by loss of memory and energy.-Aug. 22nd: Discharged recovered. - Weight : March, 100 lb.; April, 115 lb.; May, 124. lb. ; June, 139 lb.; July, 138 lb.; August, $141 \mathrm{lb}$.

CASE 2.-Sarah S__ aged thirty-seven, married, housewife, from Doncaster, admitted A pril 24th, 1871. Has been intemperate; became insane a week ago. Is in a state of extreme maniacal excitement; talkative, restless, and violent; pulse 120 ; pupils of average size, but sluggish ; tongue and lip: dry and covered with sordes; muscles hard and rigid. Ordered two drachms of the succus conii three times a day.May 8th : Quiet and rational; pupils widely dilated; pnlso 80.-11th : Convalescent. Discontinue conium.-July $\tau^{\text {th }}$ : Discharged recovered.-Weight: April, $91 \mathrm{lb}$.; May, $94 \mathrm{ll}$. ; June, 106 lb. ; July, 112 lb.

Case 3 -Lavinia $\mathrm{B}-$, aged thirty-five, widow, domestic servant, from Huddersfield, admitted A pril 25th, 1871. Had a previous attack nine years ago. No cause known for present attack, which commenced a week aggo. Is highly excited, shrieking, whistling, and fighting; sleepless, and requires to be fed. Ordered balf a drachm of tincture of cannabis indica and a drachm of bromide of potassium thrice daily.-April 29th: No better; is very noisy, and has not slept since admission; kicks and bites all who approach her; face and ears much flushed; pupils contracted; eses injected; lips and tongue dry ; pulse $1 \overline{2} 6$. To omit previous mixture, and take two drachms of succus conii every four hours. - 30th: Quieter; face less flushed; pulse 92.-May 1st: Has slept well all night, but is again greatly $\in \mathbf{x}-$ cited; takes her food well. Ordered four drachms of the succus.-2nd : Has again slept well, and is now much quieter. T'o take the conium only twice a day.-4th : Quiet, but confused in her ideas. Complains of pain, weakness, and numbness in her limbs. -6th: Convalescent. Jnly 5th: Discharged recovered.-Weight: May, $126 \mathrm{lb}$; June, $128 \mathrm{lb}$.

CASE 4.-George $H$ - aged twenty-four, married, labourer, from Hunslet, admitted June 3rd, 1871. Was never. before insane. Was attacked three days ago, and has since been violently excited. Is fiercely maniacal; very restless and combative; assaults those around him ; shouts out oaths and blasphemies; fancies that he is to be buried alive and is fighting with the devil ; strips himself naked and destroys his clothes. Is a stout robust man, and enormously strong, florid complexion, brown hair, which stands out from tbe head as if bristly; muscles start and tremble as if from eagerness; conjunctivæ injected; mouth dry; pulse 109.June 4th : Has passed a restless night and is most unmanageable. To take three drachms of succus cenii every four hours.-5th : Still maniacal. Five drachms of conium every four hours.-6th: Much quieter, though still unable to converse; restless, and given to strip himself.- 8 th Quiet and rational-14th: Convalescent; complains of a strange feeling of lightness in the back of his head, and of general weakness. To omit the medicine.-August $24^{\text {r }} \mathrm{h}$ : Discharged recovered. - Weight: June, 167 lb.; July, $165 \mathrm{lb}$.

CASE 5.-Elizabeth R-, aged forty-seven, housewife, from Wakefeld, admitted June 3rd, 1871. No previous attack. Has been insane three weeks. Was first depressed for a fortnight, then excited. A maternal aunt died in this asylum. Is violently excited, raving incoherently. Has not slept for some time, and has refused food. Face flushed; tongue red and raw; fed with the stomach-pump; two drachms of succus conii being administered by that means also.-June 4th : Has had several hours' sleep, and is more tranquil; answers intelligontly, but cannot keep her atten- 
tion fixed; takes her food. To have three drachms of succus conii thrice daily.-5th: Is more excited, very garrulous and mischievous; bowels confined.-6th: Has slept well during the night, but is still excited and restless. To take four drachms of the succus conii every four hours.-7th : Much more composed; talks rationally, but voluminously.23rd : Convalescent.-July 23rd: Discharged recovered.Weight: June, $120 \mathrm{lb}$.; July, $130 \mathrm{lb}$.

Case 6.-Joseph H-, aged thirty-five, married, blacksmith, from North Brierley, admitted March 7th, 1871. His father died of paralysis; a paternal uncle and aunt were insane. Has suffered from domestic anxieties. Became excited eight days ago, after ten days of sullenness and depression. Is very restless and talkative; cannot remain still for a second; says that he is St. Paul. Is in fair bodily health; neck bears marks of recent blister.-March 18th: Extremely violent. To take six grains of ergotine thrice daily.-23rd: The excitement has passed off, but the patient is silent and stupid.-30th: Still quiet. To omit medicine. - May 22nd: Has again become dangerously excited. To repeat ergotine. June 11th: No better. This morning he sprang out of bed naked, and jumped through a glass door without so much as scratching himself. Ordered to leave off ergotine, and to take four drachms of succus conii thrice daily.-13th: Declined food and medicine, and remained maniacal until last evening, when he was fed by means of the stomach-pump, the succus being given at the same time. Passed a better night, and is now more tranquil; takes food and physic voluntarily.-15th: Much improved.-16th: Comparatively rational; quiet in his demeanour.-Aug. 18th: Is slowly recovering from a state of partial dementia.-October 3rd: Discharged recovered.Weight: April, 134 lb.; May, 130 lb.; June, 133 lb.; July, $133 \mathrm{lb}$; August, $137 \mathrm{lb}$.

CAsE 7.-Maria $\mathbf{P} \longrightarrow$, aged thirty-seven, married, housewife, from Saddleworth, was admitted on June 5th, 1871. Has had two children, the youngest of whom is now seventeen years old. No heredity; of temperate habits. Was under treatment in this asylum for an attack of acute mania from February 17 th to October 9 th, 1867. Grew excited eight days ago, after a short period of depression. Is now wild and ungovernable, dancing, singing, and raving. Seems to delight in movements and gesticulations, and puts forth much strength if interfered with. Ordered two drachms of succus conii every four hours.-June 6th: Half an hour after taking the medicine she becomes lethargic, then drowsy, and remains so for an hour. If roused, however, she is as noisy and exuberant as ever. Pupils of average size and equal; pulse 110 ; face pale.-7th: Quieter than when admitted, but when disturbed breaks out into maniacal excitement; any noise increases her vehemence.-16th : Quiet, but mischievous in a good-humoured jocular way; becomes excited whenever there is the least noise in the ward.July 2nd: Has gradually calmed down. To omit the medicine.-August 8th : Quite convalescent.-30th : Discharged recovered.-Woight: June, 106 lb. ; July, 126 lb.; August, $145 \mathrm{lb}$.

CASE 8. - Fanny D-, aged thirty-five, married, housewife, from North Brierley, was admitted May 8th, 1871. Her youngest child is fifteen months old. The violent death of a brother has preyed on her mind. A week ago she became suddenly excited, and has since been uninterruptedly noisy, violent, and destructive. - 9th: Very noisy; talks incessantly and incoherently, and attitudinises. There is a diastolic murmur at the base of the heart. She is greatly emaciated, but active and vigorous. Ordered three drachms of succus conii thrice a day. - 12th: Now composed and rational. - 23rd : Convalescent. - June 2nd: Slightly despondent.-Jul5 25th: Again quite convalescent.-Aug. 1st: Discharged recrvered.-Weight: May, 104lb.; June, 107lb.; July, 114 lb.; Augnst, $1221 \mathrm{lb}$.

CASE 9. - Ann S-, agea forty.five, single, housewife, from Bradford, was admitted Niay 12th, 1871. After slight mental depression of a year and a half's duration, she became excited ten days ago. Is now talking perpetually in a loud, harsh voice, and will not remain in one place. She apparently understands what is said to her, but $r \in p$ plies in unintelligible jargon. Face and head much flushed; pupils contracted; pnlse 90 ; skin cool; tongue very foul. Ordered two drachms of succus conii every fourth hour. - 16 th: Still very maniacal ; requires to be fed with the stomach-pump. The dose of succus conii to be increased to four and then to six drachms. - 18th: Now takes her food voluntarily; is much quieter, but talks incoherently. - 19th: Quite rational ; medicine only twice a day. - 23rd: Improving. To omit the medicine. - June 20th: Convalescent. Sept. 4th : Discharged recovered. - Weight : May, $112 \mathrm{lb}$; June, 126 lb.; July, 130 lb.; August, $137 \mathrm{lb}$.

CASE 10.-Elizabeth $\mathrm{H}-$, aged forty-three, married, housewife, from Huddersfield, admitted May $30 t \mathrm{t}, 1871$. Was insane for a short time three years ago. Has had six children; the youngest is now five years old. A brother and one of her own children have died of epilepsy, and one sister has had puerperal mania. The present attack commenced eight weeks ago, and has been characterised by gradually graves. cent excitement.-31st: Excited and out of bed all night. Will not answer questions, and is very restless and fidgety. Fairly nourished. Skin of the face and forearms bronzed. Ordered two drachms of succus conii three times a day.June 1st: Has been quiet during the night, and continues so this morning.-9th: Convalescent.-Bept. 12th: Would have been discharged some time ago, but has been detained with her own sanction because of an attack of hepatic disease. - Nov. 7th: Discharged recovered. - Weight: June, 124lb.; July, 132 lb.; Aug., 131 lb.; Sept., 1341b.; Oct., $131 \mathrm{lb}$; Nov., $135 \mathrm{lb}$.

On a future occasion I hope to have an opportunity of recording the results obtained in the treatment of certain mental diseases by conium in combination with opium and hyoscyamus.

January, 1872.

\section{DISEASE OF RIGHT INTERNAL EAR AND RESULTING ABSCESS IN THE BRAIN.}

\section{By A. O. HASLEWOOD, M.R.C.S., T.S.A.}

Mr. H-, aged forty, called on me on May 9th. For the last five or six years he has had a running from his right ear, with occasionally slight bleeding. The discharge would from time to time cease for a week or so, and this cessation was always followed by increased distress in the head and a slight eruption of herpes, which disappeared as the ear resumed its discharge. Memory defective; difficulty in concentrating his attention for long upon any subject; of ten asks questions, and, before he can be answered, will start another and quite different topic; staggers in his walk, so that he has been thought to be in liquor when quite sober; feels very giddy, and has occasionally a feeling as if he was turning round; has had constant pain for the last eighteen months; extremities cold; can't take wine or spirits, as they "fly to the head." He had a fall from a horse some years ago, and in the summer of $1867 \mathrm{had} \mathrm{a}$ slight sunstroke. Has had a slight purulent oozing from a minute orifice at the back of his head; this never continues long, but is constantly recurring at intervals of a few weeks. Pulse 80 ; bowels regular; has had no sound sleep for months. I put him on the iodide of potassium (five grains) and decoction of chinchona; the ear to be gently syringed every morning with warm water containing one-fortieth part of carbolic acid.

He improved considerably under this treatment. I may here say that there was no history of syphilis. He has been married twelve months, and has a child a few weeks old.

On May 20th, feeling very well, he undertook, without my knowledge, a long drive in a hot sun. He was much exhausted on reaching home, and in great pain and feeling drowsy. He rallied with rest and restoratives. Iodide of potash and chinchona decoction to be continued.

June 7th. - Severe neuralgia, with deep-seated pain in head. This was much relieved by the application of leeches and dry-cupping, and an increased dose of iodide of potash at bed time (fifteen grains).

9tb.- Hid a consultation with Mr. Beevor, of Manchester, who confinmed the serious diagnosis which I bad formed. He ordered him a mixture of calomel, potassio-tartrate of antimony, and opium, in the form of pill, to be taken every four bours, with chloral at bed time; also to continue poultice to the ear, and to have a small blister behind the ear every third day. 